\title{
Effect of rotation rate on microstructure and texture evolution during friction stir welding of Ti-6Al-4V plates
}

\author{
.Sungook YOON*, Rintaro UEJI, Hidetoshi FUJII
}

Joining and Welding Research Institute, Osaka University, Ibaraki, Osaka 567-0047, Japan

*Corresponding author, E-mail: yoon@jwri.osaka-u.ac.jp, yoonsungook@gmail.com, Tel./fax: +81668798663 .

\begin{abstract}
Ti-6Al-4V alloy plates with a thickness of $2 \mathrm{~mm}$ were successfully friction stir welded (FSW) and the microstructure change in the weld was clarified. The FSW was conducted at the tool rotation rates ranging from 225 to $300 \mathrm{rpm}$ under the constant tool traverse speed of $50 \mathrm{~mm} / \mathrm{min}$. The microstructure of the stir zone exhibited inhomogeneous distribution along the plate thickness due to the temperature gradient caused by the lower thermal conductivity. The microstructure of the stir zone consisted of two types of morphologies. The fully lamellar structure was observed near the top surface, while the fully equiaxed structure was observed near the bottom surface. At the intermediate area between the top and the bottom regions, a mixed microstructure having both lamellar and equiaxed $\alpha$ grain morphologies was observed. The change in texture is also quite consistent with the microstructure distributions. This inhomogeneity was mainly due to the change in the microstructure development processes that involve phase transformation or plastic deformation.
\end{abstract}


Keywords: Ti-6Al-4V alloy, friction stir welding, microstructure, texture, $\beta$-transus temperature

\section{Introduction}

Ti-6Al-4V, which accounts for about half of all the titanium (Ti) products, is being widely applied in many industrial fields due to its high strength, creep resistance, fatigue resistance and castability with lower specific density[1,2]. However, Ti alloys are not easily welded by conventional fusion welding techniques because the quality of the welded joint deteriorates due to the formation of a brittle and coarse microstructure, severe welding deformation and high residual stress[3]. Therefore, a more suitable welding method should be established. Friction stir welding (FSW) has been actively studied for Al [4-8] alloys as a new solid-state welding process since it was invented by The Welding Institute (TWI) in 1991. Recently, much attention has been paid to the FSW of high melting point materials such as steel [12-14] and Ti alloys [15-27], because the solid state joining process can avoid or minimize the problems associated with melt/solidification welding. Therefore, the FSW of Ti and its alloys is expected to more adaptable than conventional fusion welding technologies.

Several studies on the microstructure of the FSWed Ti-6Al-4V have been reported [1719,22,24-27]. In the stir zone of FSWed Ti-6Al-4V, different types of microstructures can be obtained depending on the thermal cycle. When the peak temperature exceeded the $\beta$-transus temperature, the microstructure of the stir zone exhibited fully lamellar structure which reduces the ductility [26]. Kitamura et al. [22] studied the FSW of Ti-6Al-4V plates at a peak temperature lower than the $\beta$-transus temperature and they successfully obtained the fully equiaxed structure in the stir zone. The change in the microstructure has a significant effect 
on the mechanical properties of the joints. The joint having the fully equiaxed structure showed mechanical properties superior to that of the fully lamellar structure joint.

In addition, the FSW joint generally has an inhomogeneous distribution of microstructures which is closely related with the mechanical properties of the weld. The distribution should be due to the metal flow as well as the temperature distribution. The poor thermal conductivity of Ti-6Al-4V can possibly lead to a significant temperature gradient along the plate thickness since the heat is mostly generated at the top surface where the input heat mainly occurs due to the friction. Thus, there is the possibility of a microstructural inhomogeneity especially in the stir zone where various kinds of microstructure morphologies were reported as already mentioned. The majority of previously reported studies examined the effect of the welding conditions on the microstructure and the mechanical properties of FSW of Ti-6Al-4V plates. Zhang et al. [26] and Su et al. [27] performed the FSW at a temperature above the $\beta$-transus and they pointed out the mechanical properties of the joints increased with the decreasing in the heat input. Lie et al. [17], Zhou et al. $[18,19]$ performed FSW or friction stir processing of Ti-6Al-4V plates and reported that the microstructure of the stir zone exhibited a mixture of the equiaxed $\alpha$ grains with the $\alpha+\beta$ lamellar structure. This microstructure of the stir zone indicates that the peak temperature was just below the $\beta$-transus temperature. In addition, they also pointed out that the mechanical properties of the joints increased with the decreasing in the heat input. As mentioned above, the lower thermal conductivity is one of the characteristics of the Ti-6Al-4V and it may provide a thermal distribution in the FSW of Ti-6Al-4V joints. However, the relationship between the process peak temperature, the microstructure and the mechanical property distribution in the stir zone has not been clearly established yet. In this study, the FSW of Ti$6 \mathrm{Al}-4 \mathrm{~V}$ plates was performed at various tool rotation rates and the inhomogeneous distribution of the microstructure in the stir zone along the plate thickness was investigated. 


\section{Experimental procedures}

Figure 1 shows a schematic illustration of the FSW process. Ti-6Al-4V plates with a thickness of $2.0 \mathrm{~mm}$, a width of $35 \mathrm{~mm}$ and a length of $300 \mathrm{~mm}$ were used as the base metal. The chemical compositions of the base metal is $6.2 \mathrm{Al}-0.18 \mathrm{Fe}-0.019 \mathrm{C}-3.87 \mathrm{~V}-0.14 \mathrm{O}-0.009 \mathrm{~N}-$ balance Ti (in wt\%). A tungsten carbide-based alloy tool, which had a $15 \mathrm{~mm}$ shoulder diameter, a $6 \mathrm{~mm}$ probe diameter and a $1.8 \mathrm{~mm}$ probe length was used. Argon shielding gas was continuously employed to prevent oxidation of the joints. The tool rotation axis was tilted by $3^{\circ}$ to the tool traverse direction. The tool rotation rate was changed in a range from $225 \mathrm{rpm}$ to $300 \mathrm{rpm}$ at a constant tool traverse speed of $50 \mathrm{~mm} / \mathrm{min}$. The temperature changes during the process were measured at the weld line of the bottom plate using a thermocouple as shown in Fig. 2. The temperature measurement was conducted at three positions on the weld line and the highest temperature of the three measurements was adopted as the process peak temperature. The microstructure of the stir zone was observed by optical microscopy (OM), scanning electron microscopy (SEM) and electron back scattering diffraction (EBSD) measurements. In order to prepare the specimen for the microstructure observation, the weld was cut perpendicular to the welding direction and the transverse cross section ground. The specimen for the $\mathrm{OM}$ observations was etched in a $2 \mathrm{ml} \mathrm{HF}+6 \mathrm{ml} \mathrm{HNO}_{3}+92 \mathrm{ml}$ water solution. The specimen for the SEM and EBSD observation was electrolytically polished in a $5 \mathrm{mlHClO}_{4}+35 \mathrm{mlC}_{4} \mathrm{H}_{9} \mathrm{OH}+60 \mathrm{ml} \mathrm{CH} 3 \mathrm{OH}$ solution at a voltage of $30 \mathrm{~V}$ at $-40^{\circ} \mathrm{C}$. The $\alpha$ phase crystallographic orientation measurement of the stir zone was carried out by EBSD with a scan area of $80 \mu \mathrm{m} \times 200 \mu \mathrm{m}$ at a step size of $0.2 \mu \mathrm{m}$. The EBSD scan was performed at an indexing rate of 120 indexed patterns/second. In order to ensure the reliability of the 
EBSD data, the grains having the grain tolerance angle smaller than 15 dge. were removed from the data using the grain-dilation option in the TSL OIM ${ }^{\mathrm{TM}}$ software.

\section{Results and discussion}

\subsection{Microstructure of base metal}

Before the FSW trials, the microstructure of the base metal was examined. Figure 3 (a) shows the backscattered electron image of the base metal obtained by SEM. The microstructure of the base metal consisted of equiaxed $\alpha$ grains with a mean grain size of about $4 \mu \mathrm{m}$ and retained $\beta$ phase. The EBSD measurement clarified that the volume fraction of the $\beta$ phase was about $4.5 \%$ located at the $\alpha$ grain boundaries. Figure 3 (b) shows the $[0001] \alpha$ pole figure measured at the base metal. The $\alpha$ phase texture of the base metal consisted of the typical rolling texture of Ti-6Al-4V in which the c-axis tends to be parallel to the transverse direction of the plane. This texture, which is the so-called basal/transverse texture, is frequently found when the deformation was performed at the temperature where the $\alpha$ phase is mainly present at the deformation temperature $[28,30]$.

\subsection{Process peak temperature}

Figure 4 shows the process peak temperature at various tool rotation rates. Under all the FSW conditions, the temperature increased when the tool approached the measurement position and reached the peak temperature when the tool was located above the measurement point. These peak temperatures did not exceed the $\beta$-transus temperature $\left(980{ }^{\circ} \mathrm{C}\right)$ under all 
the welding conditions. The peak temperature increased with the increasing tool rotation rate. A similar tendency has been already reported in a previous study on the FSW of Ti-6Al$4 \mathrm{~V}[22]$.

\subsection{Weld macrostructure}

Figure 5 shows the optical macrographs of the cross-section perpendicular to the tool traverse direction of the FSW joints at various tool rotation rates. The horizontal and the vertical directions of these figures are parallel to the transverse direction (TD) and the normal direction (ND) of the joints. The advancing and retreating sides are the left and right sides, respectively. There was no defect such as void, crack and unwelded zone in the stir zone, showing that the defect-free joints were successfully obtained in all the joints. Basin-shape stir zones were clearly visible at the center of the FSW joints which widens from the bottom surface to the top surface due to the friction between the shoulder and the top surface of the base metal. This stir zone morphology is similar to the previous studies on the FSW of Ti or its alloy $[21,22]$. The area of the stir zone increased with the increase in the tool rotation rate. This result suggests that the volume of the stirred material increased with the increase in the tool rotation rate.

\subsection{Microstructure of weld}

The microstructure of the stir zone obtained at the various tool rotation rates are shown in Fig. 6 to Fig. 8. The microstructure morphology in all the stir zones exhibited inhomogeneous distribution along the plate thickness direction. Figure 6 shows the backscattered electron images of the center of the stir zone obtained at $300 \mathrm{rpm}$. These images were taken at the 
locations indicated on the cross section optical image in Fig.5 (a). These microstructures consisted of an area showing a mixture of the equiaxed $\alpha$ grains and lamellar structure and the fully lamellar structure area. Figure 6 (a) shows the microstructure of the stir zone $0.8 \mathrm{~mm}$ below the top surface where the fully lamellar structure was present. The microstructure suggests that the peak temperature exceeded the $\beta$-transus temperature [26,27]. The fully lamellar structure area was the $\beta$ single phase during the heating stage of the FSW process and subsequently transformed to $\alpha$ phase through the nucleation and the growth during the cooling stage of the process after the tool had passed. Figure 6 (b) through (d) show the microstructures of the stir zone $0.9,1.3$ and $1.5 \mathrm{~mm}$ below the top surface, respectively. The microstructures of locations (b) and (c) exhibited a mixture of the equiaxed $\alpha$ grains with the $\alpha+\beta$ lamellar structure. The equiaxed $\alpha$ structure distributed with a necklace-like morphology, which indicates that the equiaxed $\alpha$ grains should preferably precipitate along the prior $\beta$ grain boundary. This microstructure morphology is similar to that reported by Lie et al. [17], and Zhou et al. $[18,19]$ which suggests that the peak temperature did not exceed the $\beta$-transus temperature. However, the peak temperature is considered to be just below the $\beta$-transus temperature since the lamellar structure is evolved by the phase transformation from high temperature $\beta$-phase. In other words, the microstructure in this area was evolved by the combination effect of the recrystallization and the phase transformation. When the measurement position is reached further to the bottom of the plate where the corresponding image is (d), the almost fully equiaxed $\alpha$ grain structure was found and the mean $\alpha$ grain size is $1.1 \mu \mathrm{m}$.

Figure 7 shows the backscattered electron images of the center of the stir zone obtained at $250 \mathrm{rpm}$. The measurements were conducted at the areas indicated in Fig.5 (b). The transition of the microstructure through the thickness looks similar to that found in the $300 \mathrm{rpm}$ joint. 
That is, the lamellar structure can be found near to the top surface and the area fraction of the equiaxed structure increases with the increase in the distance from the top surface. When compared to the microstructures at a location $1.3 \mathrm{~mm}$ below the top surface (Fig.6 (c) and Fig.7 (c)), it is observed that the area fraction of the equiaxed structure increases with the decreasing tool rotation rate. Figure 7 (d) shows the microstructure of the stir zone at a location nearest to the bottom surface. This microstructure exhibited the fully equiaxed structure whose mean $\alpha$ grain size was about $0.8 \mu \mathrm{m}$. This microstructure morphology is similar to that reported by Kitamura et al. [22] which indicates that the peak temperature was significantly lower than the $\beta$-transus temperature. The fully equiaxed structure implies that the $\alpha$ phase was plastically deformed and the volume fraction of $\alpha$ phase is high enough to form the fully equiaxed microstructure at elevated temperature.

When the tool rotation rate decreased to $225 \mathrm{rpm}$, most of the stir zone showed an equiaxed microstructure as shown in Fig. 8. The measurements were conducted in the areas indicated on the cross section optical image in Fig. 5 (c). The equiaxed microstructure can be found even in image (a) nearest to the top surface. In addition, the grain size of the equiaxed $\alpha$ structure was $0.8 \mu \mathrm{m}$ which is the finest size of all the observed data. The microstructures of the stir zone $0.5 \mathrm{~mm}$ and $0.9 \mathrm{~mm}$ below the top surface obtained at $225 \mathrm{rpm}$ are shown in Fig. 8 (c) and (d), respectively. The microstructures of these locations exhibited the fully equiaxed structure, and the equiaxed $\alpha$ grain sizes of these locations were about $0.8 \mu \mathrm{m}$ and $0.7 \mu \mathrm{m}$, respectively. These grain sizes were not very different from that of the $250 \mathrm{rpm}$ joint, indicating that the rotation rate has no significant effect on the equiaxed $\alpha$ grain size at the bottom part of the joints. 
The area fraction of the equiaxed $\alpha$ grains to the lamellar structure in the stir zone along the plate thickness is shown in Fig. 9. In the stir zone obtained at the tool rotation rate of $300 \mathrm{rpm}$, only the fully lamellar structure was observed from the top surface to $0.8 \mathrm{~mm}$ below the top surface, and the fraction of the equiaxed $\alpha$ structure increased gradually in the region between $0.8 \mathrm{~mm}$ from the surface and the bottom. The gradual increase in the equiaxed $\alpha$ can also be found in the other two joints, but the location where the increase start changed to closer to the surface with the increasing in the rotation rate.

As shown in Fig. 9, the $225 \mathrm{rpm}$ joint shows the equiaxed $\alpha$ structure at the widest part. In order to examine whether any change can be found in the region with the equiaxed area, EBSD measurements were conducted. No significant difference was found in the $\alpha$ grain sizes at the different locations, but the grain boundary character changed. Figure 10 shows the mean spacing of the low angle boundaries whose misorientation angle, $\theta$, is from $1^{\circ}$ to $15^{\circ}$. The spacing increased with the increasing in the depth from the top surface. This result indicates that the dislocation density decreased since the low angle boundaries can be regarded as a substructure constructed by dislocations.

\subsection{Stir zone texture}

Figure 11 shows the [0001] $\alpha$ pole figures measured by EBSD at the stir zones of the joints obtained at the tool rotation rates of (a) 300 and (b) $225 \mathrm{rpm}$. The measurements areas (A, B, C, D, E) are indicated on the schematic illustration of the cross section at the top of Fig. 11. The horizontal and vertical directions of the pole figures are parallel to the TD and the ND, respectively, so that the center of the figures indicates the welding direction. The left and the right sides are the advancing and retreating sides, respectively. All these pole figures can be classified into two groups according to the orientation concentrations. Most of these showed 
one strong concentration of [0001] which is parallel to the welding direction. This type can be found in all parts of the $300 \mathrm{rpm}$ joint and the top parts (A, B, C) of the $225 \mathrm{rpm}$ joint. The remaining (D, E in the $225 \mathrm{rpm}$ joint) had a broadened concentration of [0001] which is roughly parallel to the TD. This distribution is well agreed with the microstructure distribution as shown in Fig. 9. The region with the lamellar structure had a texture with a strong concentration of [0001] parallel to the welding direction, whereas the [0001] // TD texture could be found in the area covered only by the equiaxed $\alpha$ structure. It should also be noted that the maximum intensity (Imax) tended to increase in the lamellar structure region indicating some variant selection during the phase transformation. Davies et al. [29] also pointed out that the strong concentration of [0001] in the stir zone of FSW joint of Ti-6Al-4V plates where the fully lamellar structure was evolved. The detailed mechanism for the variant selection has not been discussed, however, they assumed that a preferential growth of some variants due to thermal stresses in the stir zone resulted in the strong variant selection. This variant selection should be due to the constraint effect of the high temperature $\beta$ phase texture found before the phase transformation, although further study is needed to clarify this phenomenon. The plastic deformation behavior accompanied with the complex metal flow by FSW is still unclear, therefore, it seems difficult to clarify the mechanism how these textures were evolved. However, the good matching between the texture and the microstructure indicates the difference in the formation mechanism of the microstructure.

The significant finding of the results is two characteristic distributions in the thickness of the joints; the morphology and the grain boundary characteristics. As far as the morphology is concerned, this can be implied to be due to the phase transformation and the temperature distribution in thickness. The heat generation during the FSW is mainly due to the friction between the FSW tool and the top surface of the joint. In addition, the Ti has a low thermal conductivity so that the temperature gradient is easily developed. As shown in Fig. 4, the 
joints were heated up to the temperature near the $\beta$-transus. Consequently, the top part of the joint transforms to the $\beta$ single phase during the FSW and the amount of the $\beta$ phase increases with the increasing temperature caused by the higher tool rotation rate. It is well known that the $\beta$ phase easily changed to the lamellar structure by cooling [30], which is what happened in the FSW joint after the stirring. On the other hand, the bottom part maintained a large amount of the $\alpha$ phase because of the lower peak temperature, and the $\alpha$ phase was plastically deformed at elevated temperature. This causes the dynamic as well as the static recrystallizations which formed the equiaxed $\alpha$ grains.

The plastic deformation should be the key to clarify the mechanism for the distribution of the grain boundary character. Generally, hot deformation is characterized by the strain rate. Although there are some concerns about the strain rate during the FSW [31], it should be commonly accepted that the strain rate is well related with the width of the stir zone. In this sense, the strain rate has a distribution because the width of the stir zone decreases with the increasing depth from the top surface. The higher strain rate easily provides a higher density of dislocations so that the low angle boundaries decreased near the bottom parts.

\section{Conclusions}

Ti-6Al-4V plates with a thickness of $2 \mathrm{~mm}$ were successfully friction stir welded under different welding conditions. The microstructure and the texture distribution in the thickness of the stir zone were investigated. The following conclusions were obtained.

(1) The process peak temperature under all the welding conditions was lower than the $\beta$ transus temperature at the bottom surface of the joints. The process peak temperature increased with the increase in the tool rotation rate. 
(2) Two types of microstructural morphologies were observed in the stir zone. The microstructure of the stir zone consisted of a mixture of the equiaxed $\alpha$ grains with the $\alpha+\beta$ lamellar structure area and the fully equiaxed structure area. The region of the equiaxed $\alpha$ structure can be found at the bottom side and the thickness of the region increases with the decreasing tool rotation rate.

(3) The morphology change in thickness is due to the change in the microstructure evolution, that is, the $\beta$ to $\alpha$ phase transformation or recrystallization in the $\alpha$ phase. The low thermal conductivity of the titanium follows this distribution.

(4) In the fully equiaxed structure area, the grain boundary character changes with the thickness. The spacing of the low angle boundaries increases at the lower position of the joint.

(5) The change in the texture well agreed with the change in the microstructure morphology.

\section{Acknowledgments}

This study was conducted as a part of the Aerospace Industry Innovation ProgramAdvanced Materials \& Process Development for Next-Generation Aircraft Structures project under contract with the RIMCOF Research Center of Materials Process Technology Center, established by the Ministry of Economy, Trade and Industry (METI) of Japan. Additionally, this study was supported by the Japan Science and Technology Agency (JST) under Collaborative Research Based on the Industrial Demand, “Heterogeneous Structure Control: Towards Innovative Development of Metallic Structural Materials,', The Global COE 
Program and a Grant-in-Aid for Science Research from the Japan Society for Promotion of Science. 


\section{References}

[1]G. Lutjering, J.C. Williams, A. Gysler, "Microstructure and properties of materials", In: Li J.C.M editors, "Microstructure and mechanical properties of titanium alloys", World Scientific Publishing Co. Pte. Ltd., 2000

[2]R. Nandan, T. Debroy, H.K.D.H. Bhadeshia, "Recent advances in friction-stir welding Process, weldment structure and properties”, Prog. Mater. Sci., (53)2008, 980-1023

[3]W.H. Kerans, "Welding handbook", 7th ed., Miami, American Welding Society,1982.

[4]R.S. Mishra, Z.Y. Ma, "Friction stir welding and processing", Mater. Sci. Eng. R, (50)2005, 1-78.

[5]C.G. Rhodes, M.W. Mahoney, W.H. Bingel, "Effects of friction stir welding on microstructure of 7075 aluminum”, Scripta Mater., (36)1997, 69-75

[6]G. Liu, L.E. Murr, C.S. Niou, J.C. Mcclure, F.R. Vega, "Microstructural aspects of the friction-stir welding of 6061-T6 aluminum”, Scripta Mater., (37)1997, 355-361

[7]H.J. Liu, H. Fujii, M. Maeda, K. Nogi, "Tensile properties and fracture locations of friction stir welded joints of 2017-T351 aluminum alloy”, J. Mater. Proc. Tech., (142)2003, $692-6$

[8]I. Shigematsu, Y.J. Kwon, K. Suzuki, T. Imai, N. Saito, "Joining of 5083 and 6061 aluminum alloys by friction stir welding”, Mater. Sci. Lett., (22)2003, 353-6

[9]S.H.C. Park, Y.S. Sato, H. Kokawa, "Effect of micro-texture on fracture location in friction stir weld of Mg alloy AZ61 during tensile test", Scripta Mater., (49) 2003, 161-6.

[10]S.M. Chowdhury, D.L. Chen, S.D Bhole, X. Cao, "Tensile properties of a friction stir welded magnesium alloy: Effect of pin tool thread orientation and weld pitch", Mater. Sci. Eng. A, (527)2010, 6064-6075 
[11]Y.M. Wang, C.I Chang, C.J Lee, H.K Lina, J.C Huanga, "Texture and weak grain size dependence in friction stir processed Mg-Al-Zn alloy”, Scripta Mater., (55)2006, 637-640

[12]R. Ueji, H. Fujii, L. Cui, A. Nishioka, K. Kunishige, K. Nogi, "Friction stir welding of ultrafine grained plain low-carbon steel formed by the martensite process”, Mater. Sci. Eng. A, (423)2006, 324-330

[13]R. Nandan, G.G Roy, T.J. Lienert, T. Debroy, "Three-dimensional heat and material flow during friction stir welding of mild steel” Acta Mater., (55)2007, 883-895

[14]H. Fujii, L. Cui, N. Tsuji, M. Maeda, K. Nakata, K. Nogi, "Friction stir welding of carbon steel”, Mater. Sci. Eng. A, (429)2006, 50-7

[15]Y. Zhang, Y.S. Sato, H. Kokawa, S.H.C. Park, S. Hirano, "Stir zone microstructure of commercial purity titanium friction stir welded using pcBN tool”, Mater. Sci. Eng. A, (488)2008, 25-30

[16]S. Mironov, Y.S. Sato, H. Kokawa, "Development of grain structure during friction stir welding of pure titanium”, Acta Mater., (57)2009, 4519-4528

[17]H.J. Liu, L. Zhou, Q.W. Liu, "Microstructural characteristics and mechanical properties of friction stir welded joints of Ti-6Al-4V titanium alloy", Mater. Des., (31)2010, 1650-5

[18]L. Zhou, H.J. Liu, Q.W. Liu, "Effect of rotation speed on microstructure and mechanical properties of Ti-6Al-4V friction stir welded joints", Mater. Des., (31)2010, 2631-6

[19]L. Zhou, H.J. Liu, P. Liu, Q.W. Liu, "The stir zone microstructure and its formation mechanism in Ti-6Al-4V friction stir welds", Scripta Mater., (61)2009, 596-9

[20]S. Mironov, Y.S. Sato, H. Kokawa, "Microstructural evolution during friction stir welding of Ti-15V-3Cr-3Al-3Sn alloy”, Mater. Sci. Eng. A, (527)2010, 7498-7504

[21]W.B. Lee, C.Y. Lee, W.S. Chang, Y.M. Yeon, S.B. Jung, "Microstructural investigation of friction stir welded pure titanium", Mater. Lett., (59)2005, 3315-8. 
[22]K. Kitamura, H. Fujii, Y. Iwata, Y.S. Sun, Y. Morisada, "Flexible control of the microstructure and mechanical properties of friction stir welded Ti-6Al-4V joints", Mater. Des., (46)2013, 348-354

[23]H. Fujii, Y.S. Sun, H. Kato, K. Nakata, "Investigation of welding parameter dependent microstructure and mechanical properties in friction stir welded pure Ti joints", Mater. Sci. Eng. A, (527)2010, 3386-3391

[24]S. Mironov, Y. Zhang, Y.S. Sato, H. Kokawa, "Development of grain structure in $\beta$ phase field during friction stir welding of Ti-6Al-4V alloy” Scripta Mater., (59)2008, 27-30 [25]M. Ramulu, P.D. Edwards, D.G. Sanders, A.P. Reynolds, T. Trapp, “Tensile properties of friction stir welded and friction stir welded-superplastically formed Ti-6Al-4V butt joints", Mater. Des., (31), 3056-3061

[26]Y. Zhang, Y.S. Sato, H. Kokawa, S.H.C. Park, S. Hirano, "Microstructural characteristics and mechanical properties of Ti-6Al-4V friction stir welds", Mater. Sci. Eng. A, (485)2008, $448-455$

[27]J. Su, J. Wang, R.S. Mishra, R. Xu, J.A. Baumann, "Microstructure and mechanical properties of a friction stir processed Ti-6Al-4V alloy”, Mater. Sci. Eng. A, (573)2013, 6774

[28]C. Leyens, M. Peters, "Titanium and Titanium Alloys", In: "Structure and Properties of Titanium and Titanium Alloys”, Wiley-VCH Verlag GmbH \& Co., 2005

[29]P.S Davies, B.P Wynne, W.H Rainforth, M.J Thomas, P.L Threadgill, "Development of Microstructure and Crystallographic Texture during Stationary Shoulder Friction Stir Welding of Ti-6Al-4V”, Metal. Mater. Trans. A, (42A)2011, 2278-2289

[30]G. Lütjering, J.C. Williams, “Titanium”, $2^{\text {nd }}$ ed. Springer, 2010

[31]A.P. Reynolds, "Flow visualization and simulation in FSW", Scripta Mater., (58)2008, $338-342$ 


\section{Captions}

Fig. 1 Schematic illustration of the FSW process in this study.

Fig. 2 Schematic illustration of the thermocouple position.

Fig. 3 Microstructure and texture of base metal; (a) backscattered electron SEM image and (b) (0001) $\alpha$ pole figure.

Fig. 4 Influence of the tool rotation rate on the process peak temperature.

Fig. 5 Optical macrographs of cross-sections perpendicular to the tool traverse direction of the FSWed Ti-6Al-4V plates at various tool rotation rates under the tool traverse speed of 50 $\mathrm{mm} / \mathrm{min}$; (a) $300 \mathrm{rpm}$, (b) $250 \mathrm{rpm}$ and (c) $225 \mathrm{rpm}$

Fig. 6 Microstructure of center of stir zone obtained at $300 \mathrm{rpm}$; backscattered electron SEM image of (a) $0.8 \mathrm{~mm}$ below top surface, (b) $0.9 \mathrm{~mm}$ below top surface, (c) $1.3 \mathrm{~mm}$ below top surface and (d) $1.5 \mathrm{~mm}$ below top surface.

Fig. 7 Microstructure of center of stir zone obtained at $250 \mathrm{rpm}$; backscattered electron SEM image of (a) $0.2 \mathrm{~mm}$ below top surface, (b) $0.6 \mathrm{~mm}$ below top surface, (c) $1.3 \mathrm{~mm}$ below top surface and (d) $1.4 \mathrm{~mm}$ below top surface. 
Fig. 8 Microstructure of center of stir zone obtained at $225 \mathrm{rpm}$; backscattered electron SEM image of (a) $0.1 \mathrm{~mm}$ below top surface, (b) $0.4 \mathrm{~mm}$ below top surface, (c) $0.5 \mathrm{~mm}$ below top surface and (d) $0.9 \mathrm{~mm}$ below top surface.

Fig. 9 Area fraction of equiaxed $\alpha$ grain to lamellar structure in stir zone along the plate thickness at various tool rotation speeds.

Fig. 10 Mean LAB spacing of stir zone at $225 \mathrm{rpm}$ along plate thickness.

Fig. $11(0001) \alpha$ pole figures obtained at tool rotation rates of (a) $300 \mathrm{rpm}$ and (b) 225 rpm.(measurement positions are illustrated on macrograph above pole figures) 
Figure 1

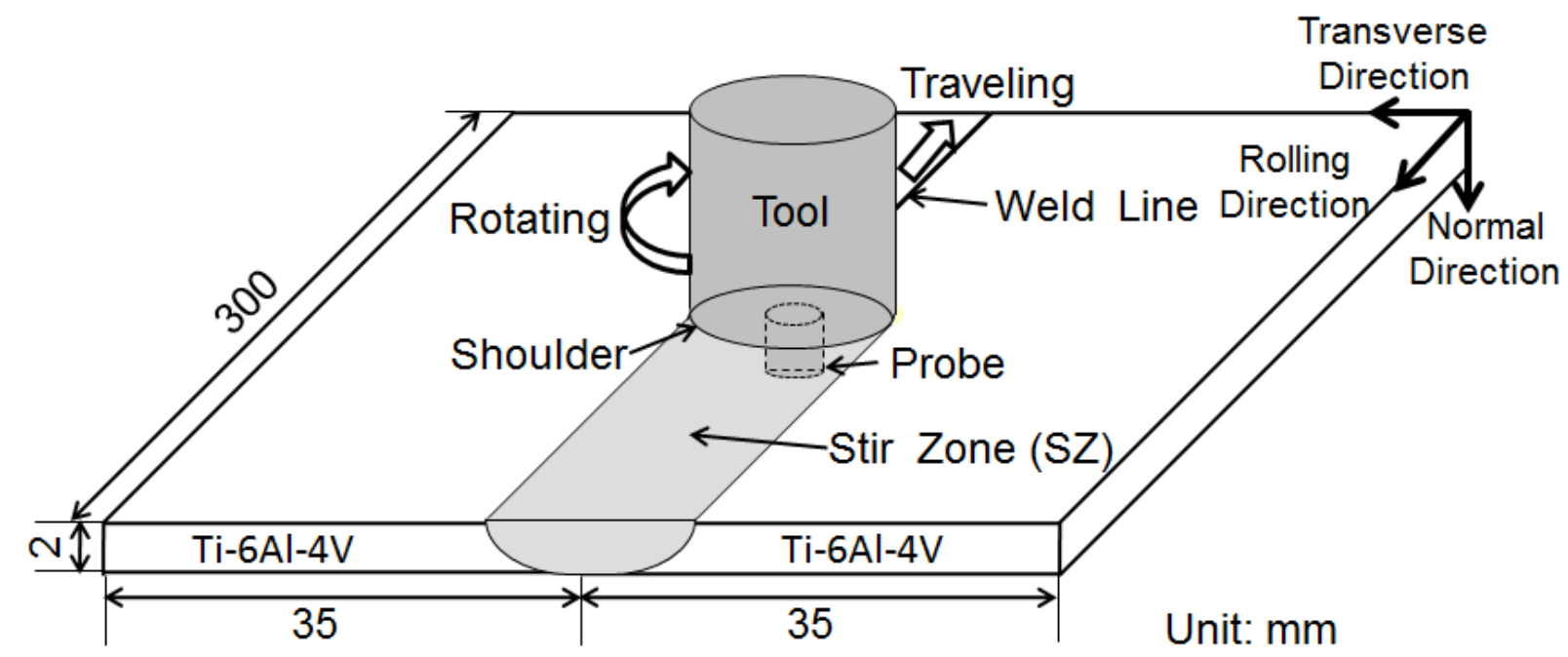


Figure 2

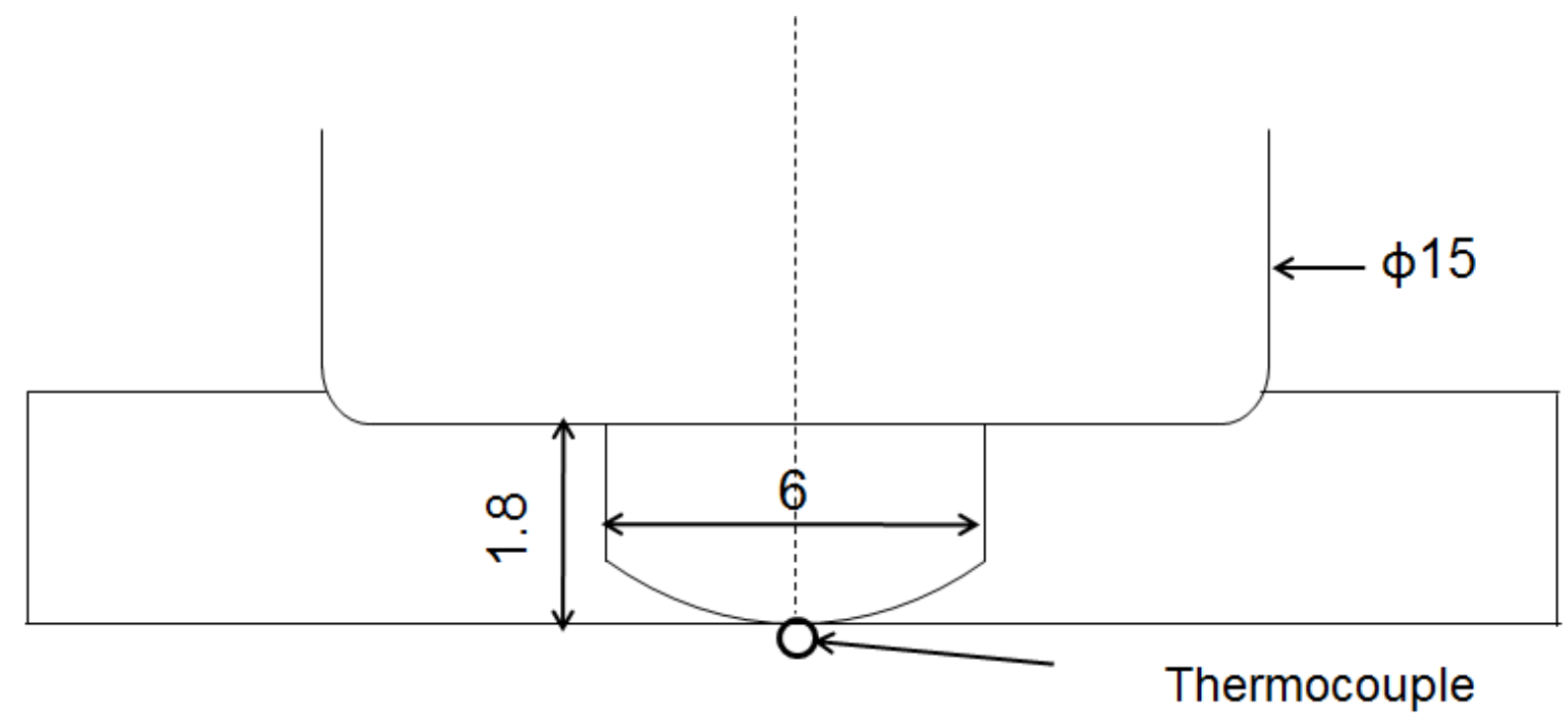

Unit: $\mathrm{mm}$ 
Figure 3

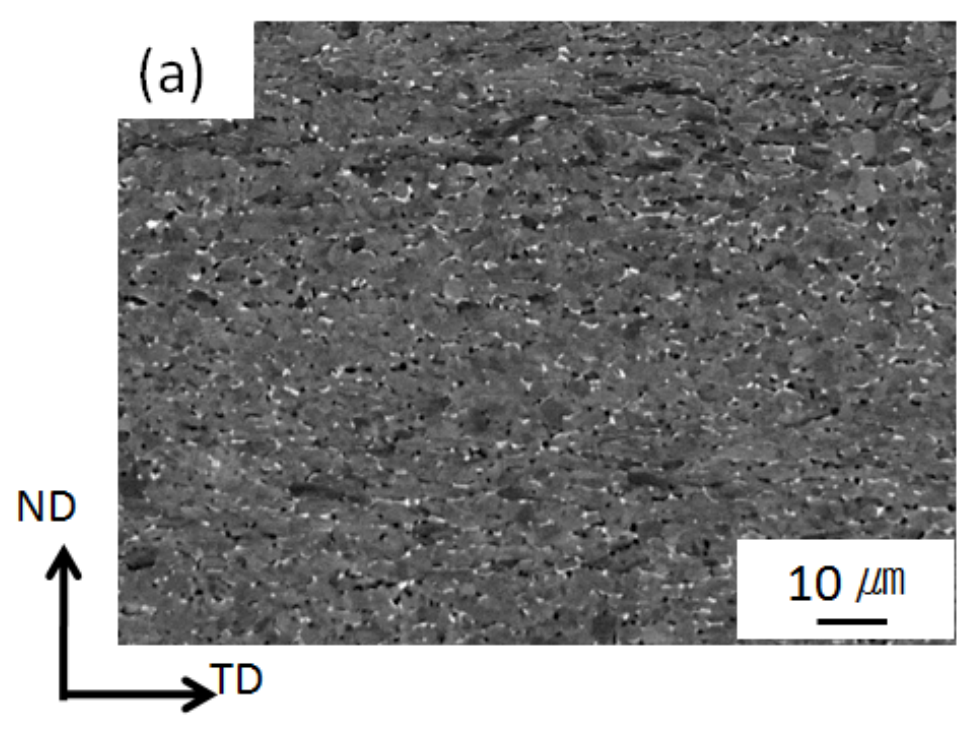

(b)

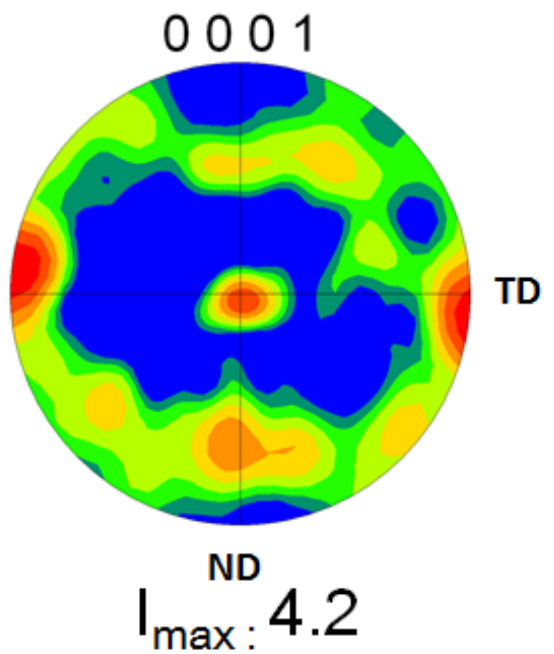


Figure 4

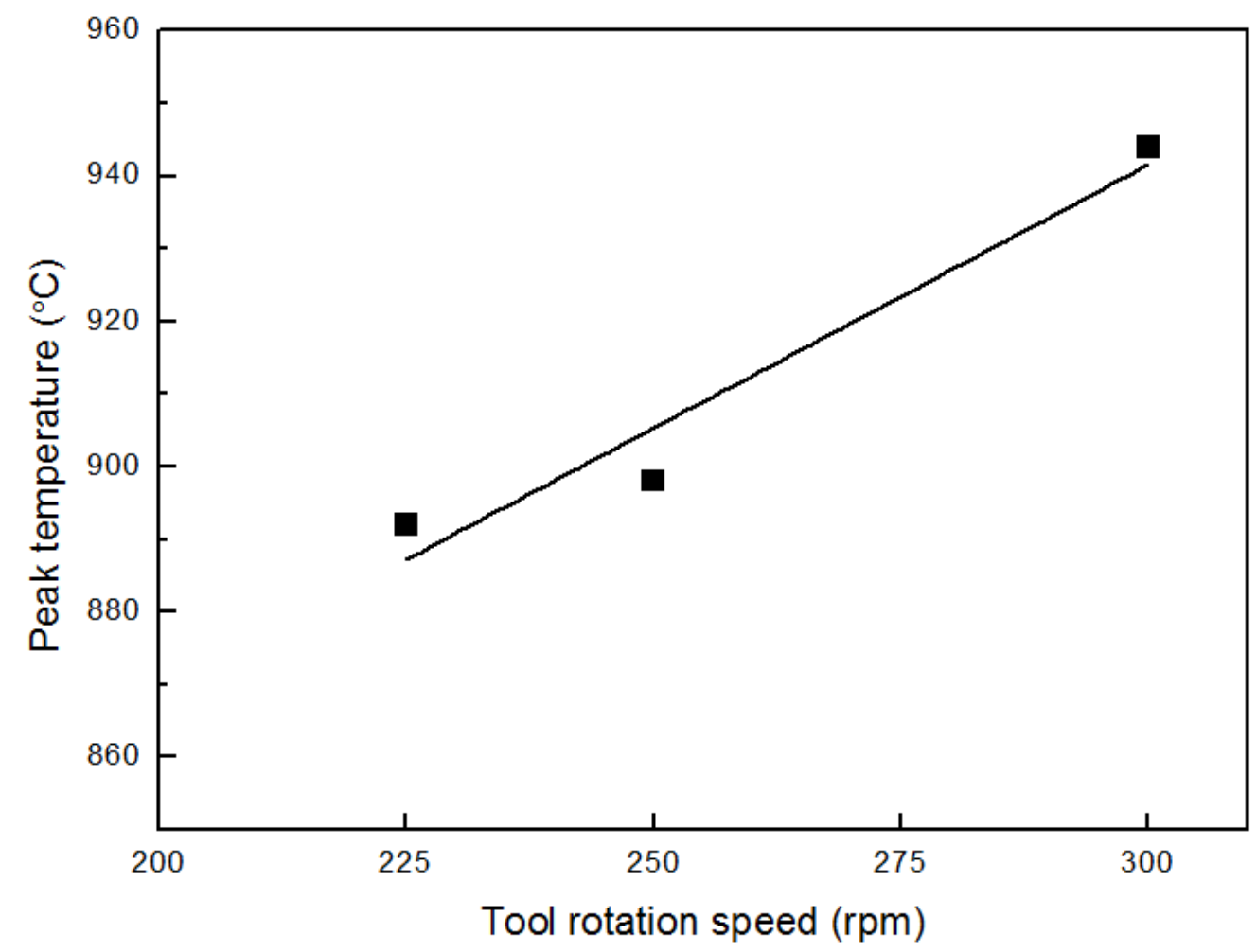


Figure 5

AS

RS
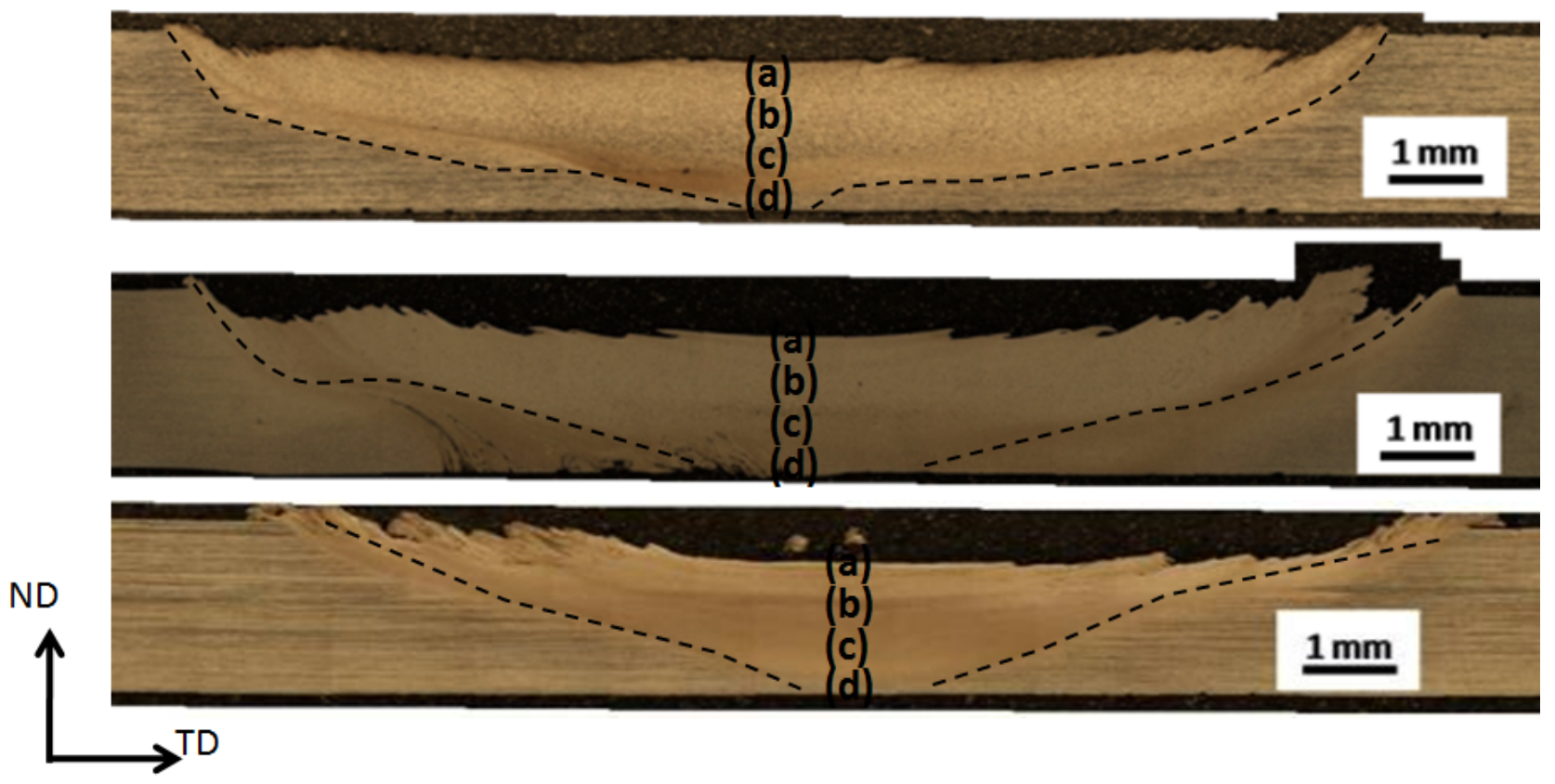
Figure 6
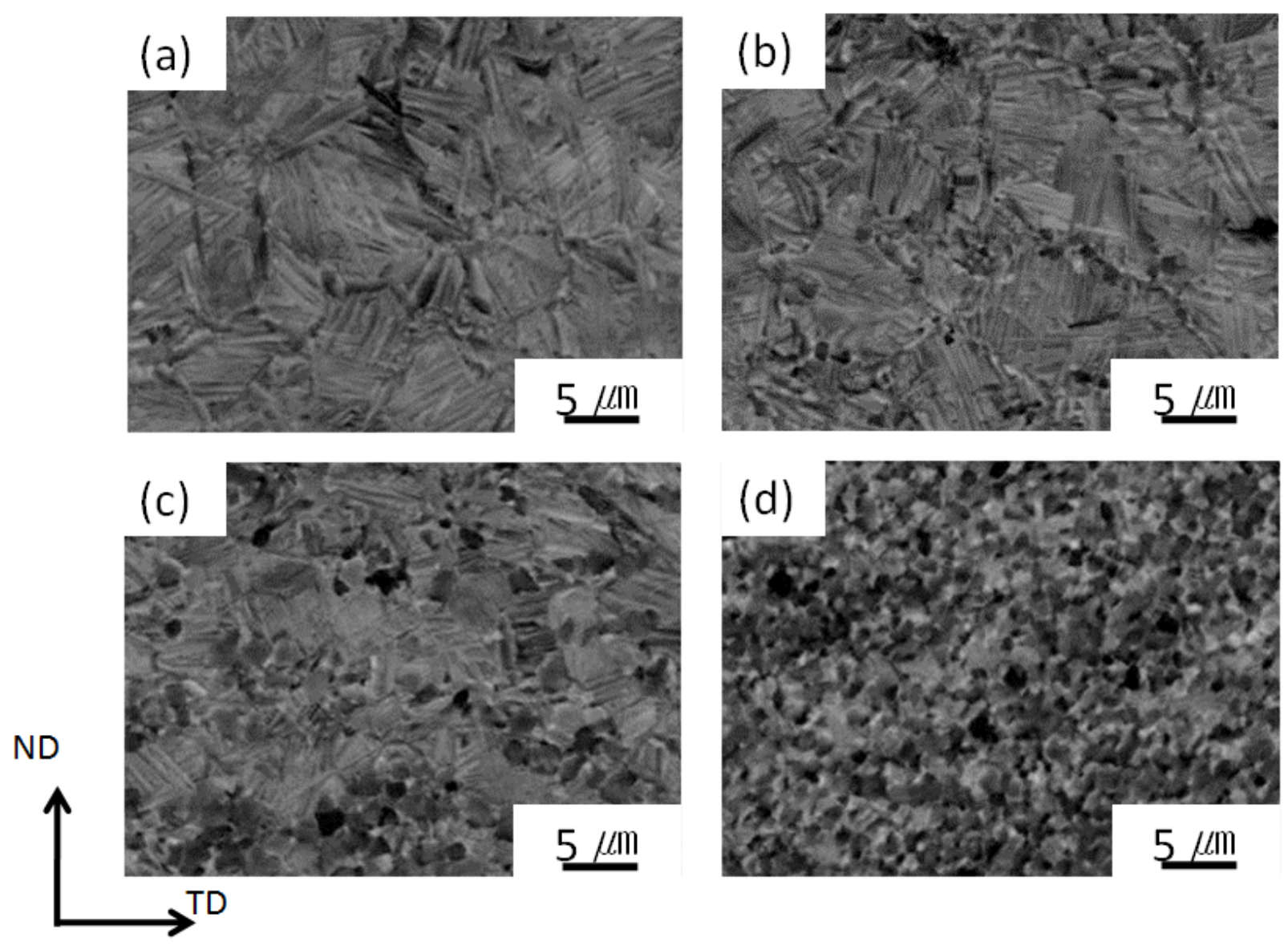
Figure 7
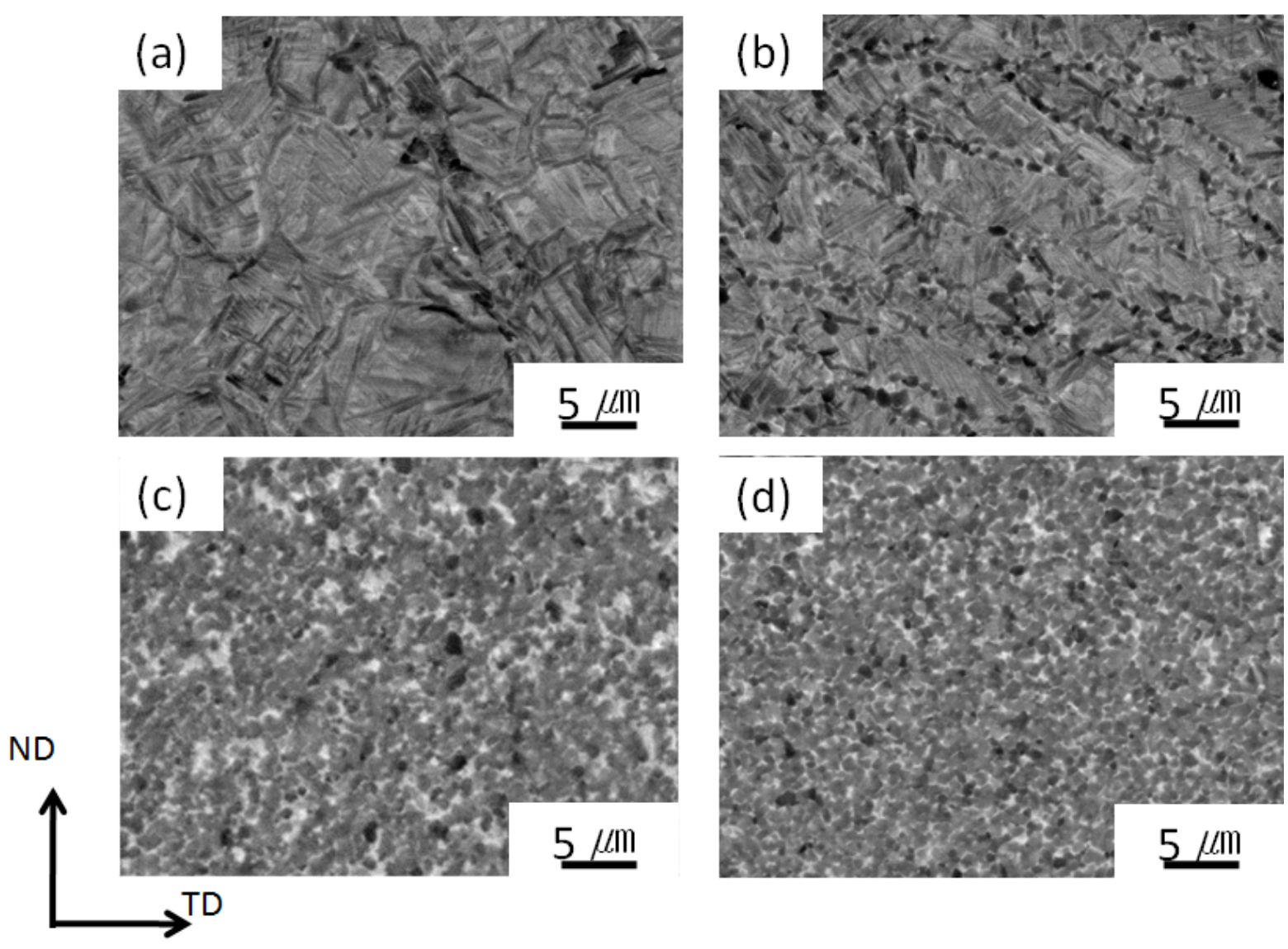
Figure 8

(a)
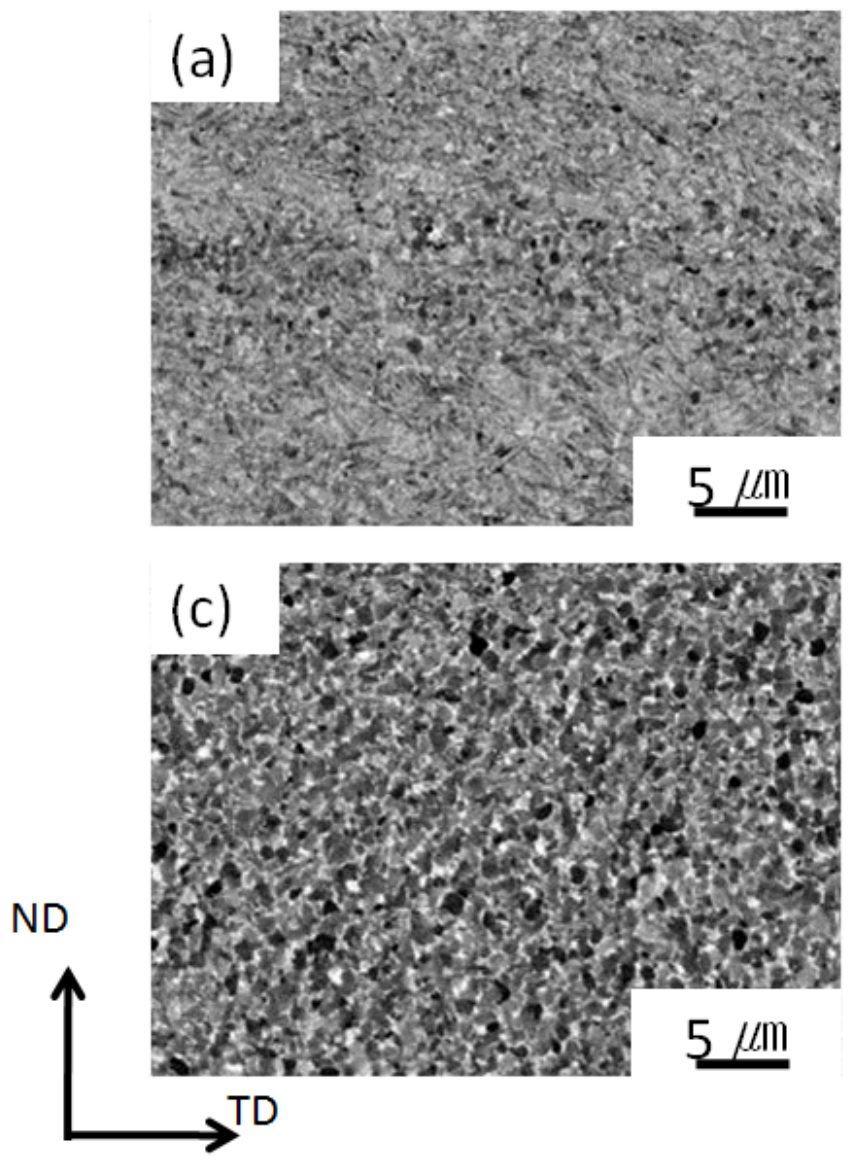

(b)
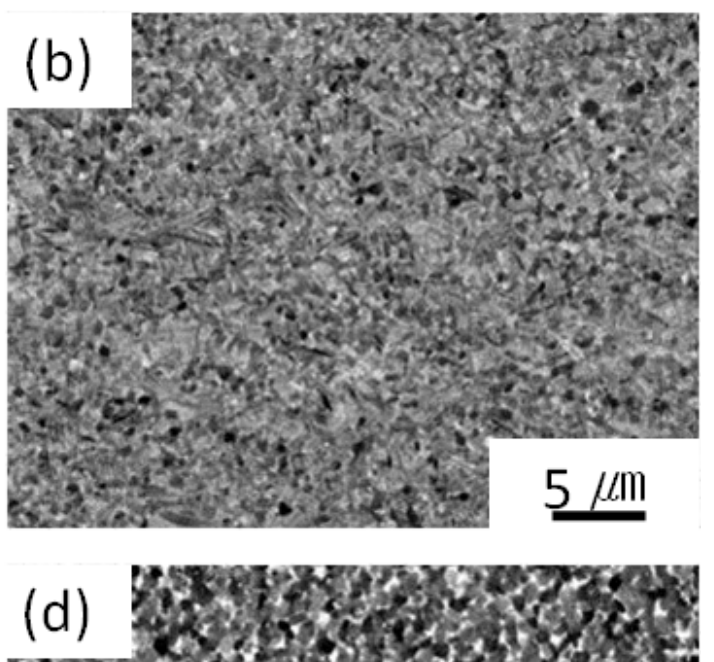

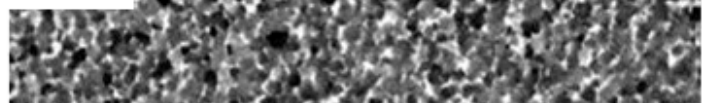

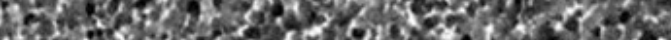

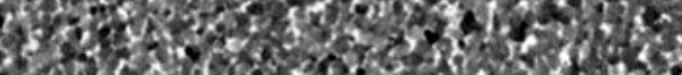
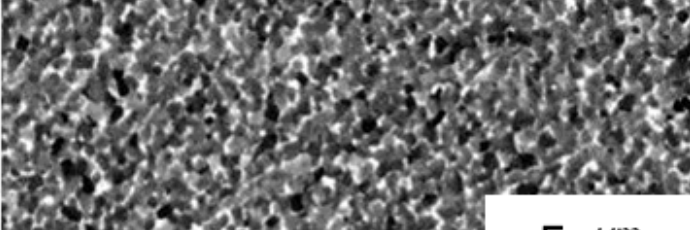

$5 \mu \mathrm{m}$ 
Figure 9

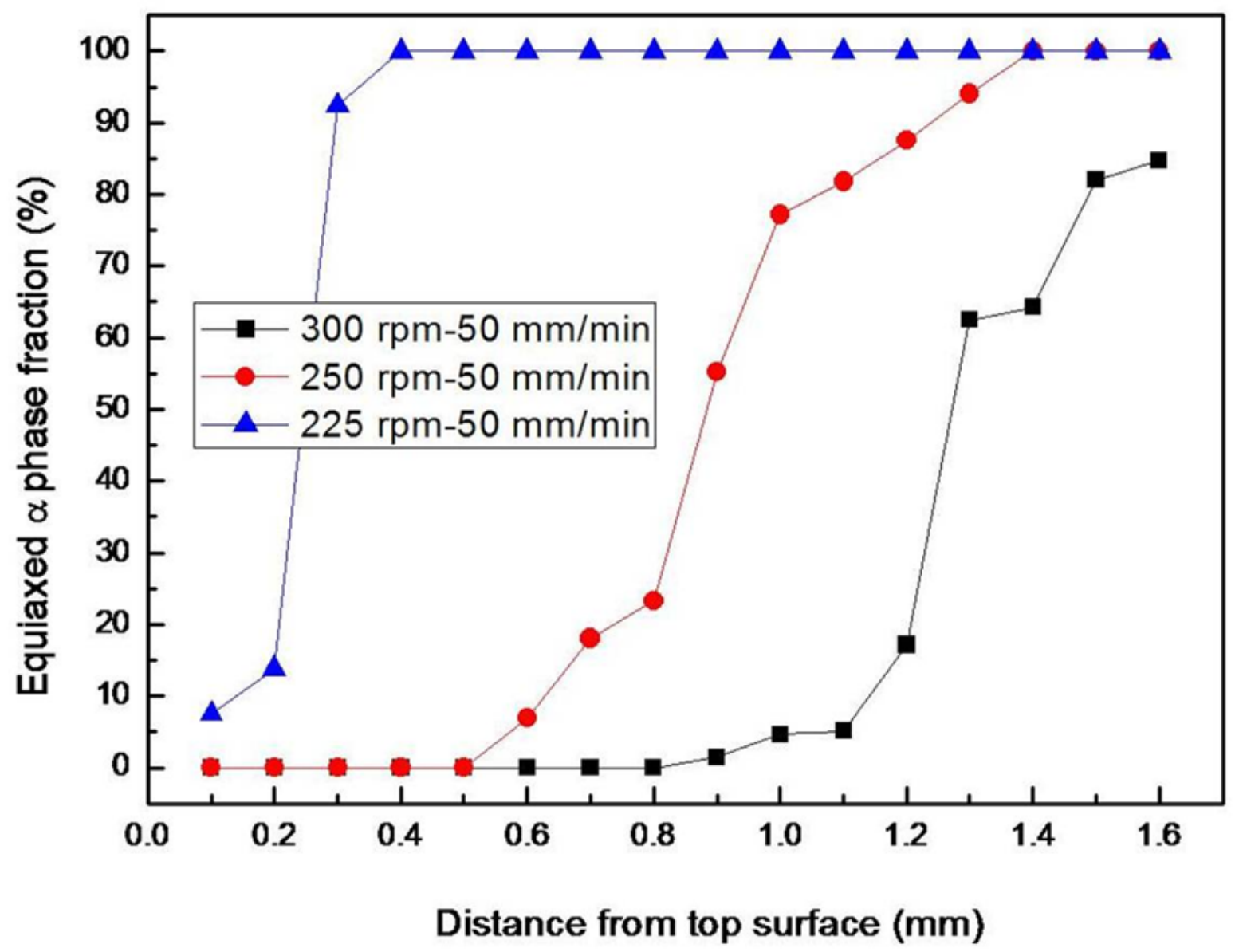


Figure 10

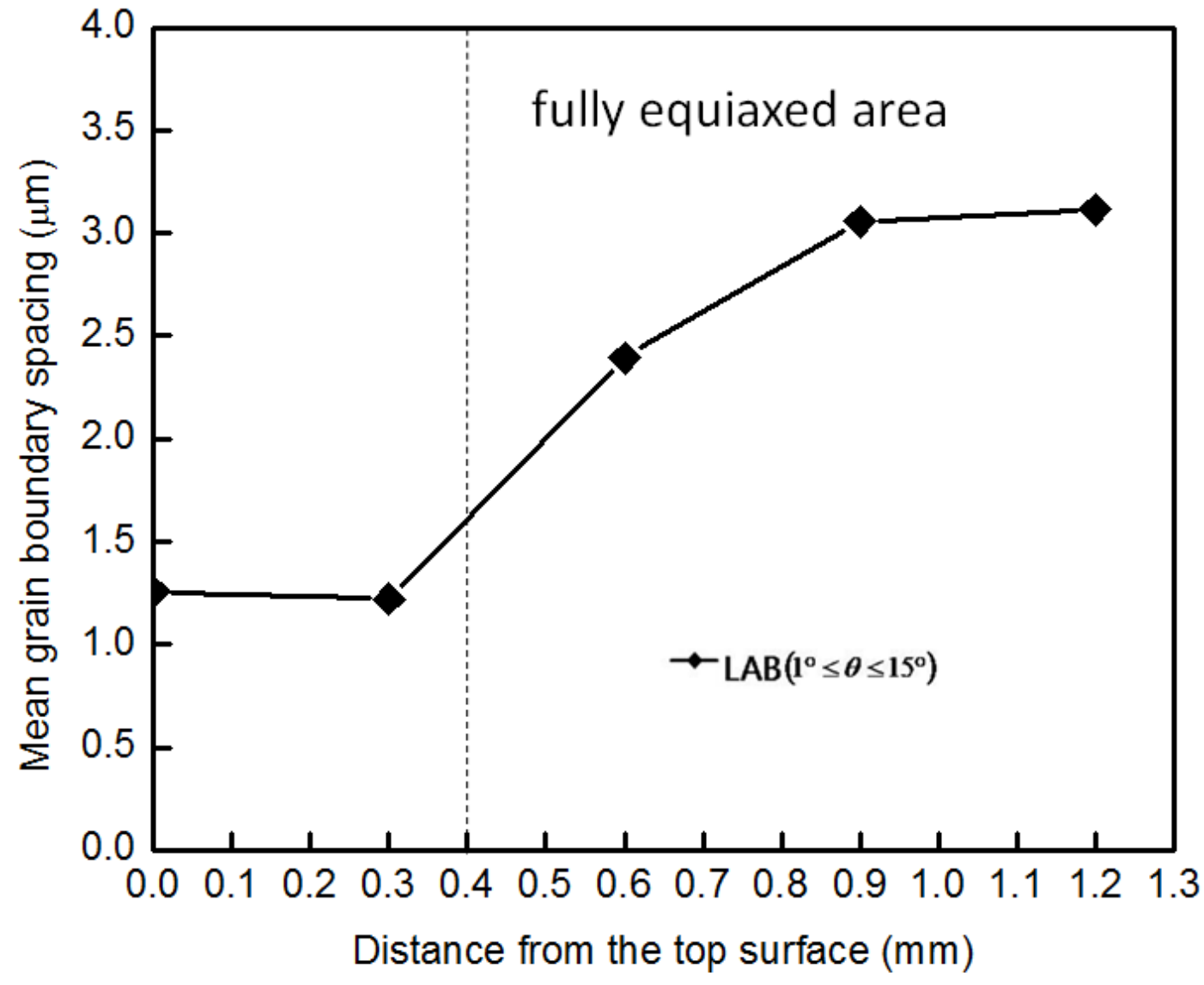


Figure 11
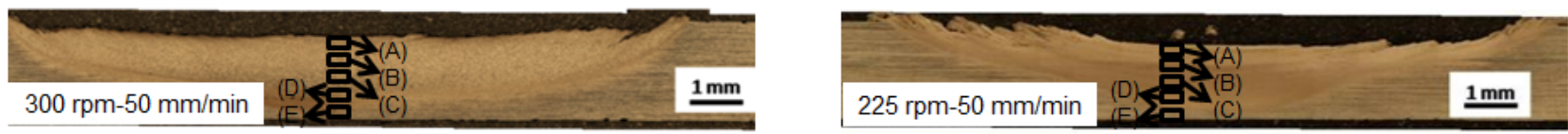

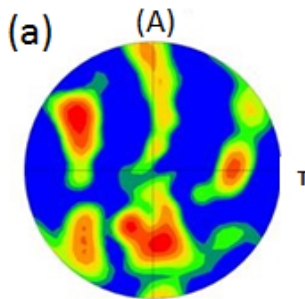

ND

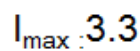

(b)

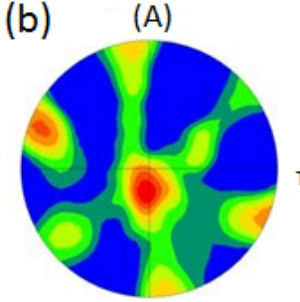

$I_{\max } 3.0$

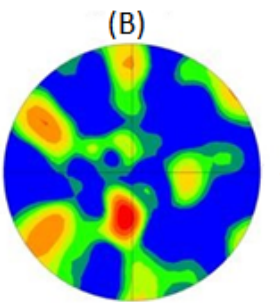

ND

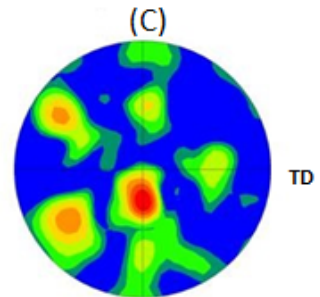

ND

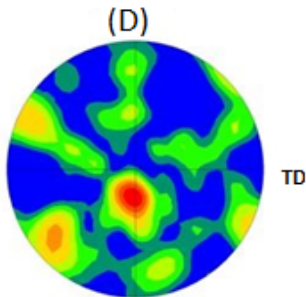

ND

$I_{\max }: 5.1$

(D)

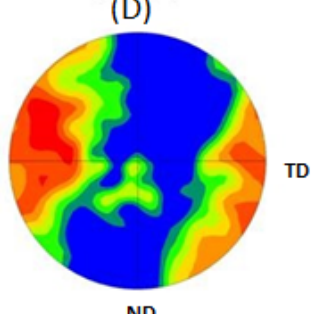

$I_{\max : 1.6}$

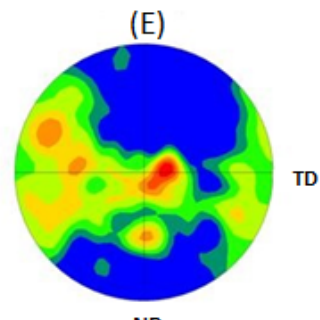

ND
(B)

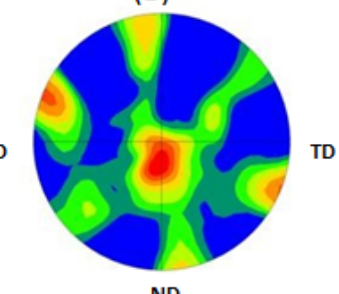

max 3.0

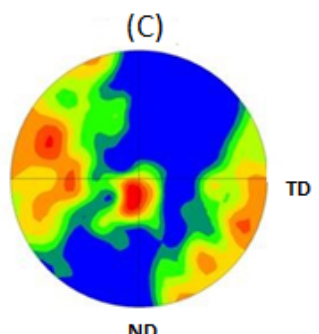

$I_{\max }: 1.5$

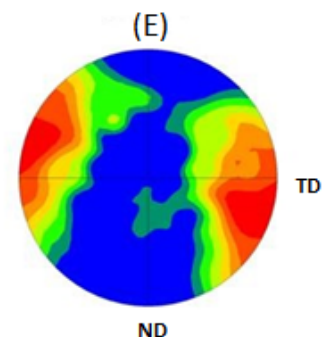

$I_{\max }: 1.6$ 